\title{
Fisiologia e produção da videira 'Niágara Rosada' nos sistemas de condução em espaldeira e em $Y$
}

\author{
Luz Angela Sanchez-Rodriguez ${ }^{(1)}$, Carlos Tadeu dos Santos Dias ${ }^{(1)}$ e Marcel Bellato Spósito(1)
}

(1)Universidade de São Paulo, Escola Superior de Agricultura Luiz de Queiroz, Avenida Pádua Dias, no 11, Caixa Postal 9, CEP 13418-900,
Piracicaba, SP, Brasil. E-mail: angelasanchez160@hotmail.com, ctsdias@usp.br, mbsposito@usp.br

Resumo - O objetivo deste trabalho foi caracterizar as variáveis fisiológicas e produtivas da videira 'Niágara Rosada' (Vitis labrusca) nos sistemas de condução em espaldeira e em Y, nos dois primeiros anos de produção. Nos ciclos produtivos de 2014 e 2015, avaliaram-se os seguintes parâmetros: índice de área foliar, fotossíntese, transpiração, condutância estomática, área de superfície foliar, variáveis de produção e qualidade do fruto. No primeiro ano de produção, houve diferenças entre os sistemas de condução quanto às variáveis ecofisiológicas influenciadas pela área de superfície foliar dos dosséis. No segundo ano de produção, não houve diferenças entre as variáveis ecofisiológicas. O número de cachos por área de superfície foliar, a massa do cacho, o número de bagas por cacho e a produção por planta não apresentaram diferenças entre os sistemas de condução. Videiras do primeiro e do segundo ano de produção não apresentaram diferenças entre os sistemas de condução, quanto às relações entre área de superfície foliar e produção; porém, a produtividade foi superior no sistema em espaldeira, em função do maior número de plantas por hectare. Frutos produzidos no sistema em Y apresentaram maior quantidade de pigmentos, como antocianinas e flavonóis, do que aqueles no sistema em espaldeira, com a mesma a quantidade de sólidos solúveis totais.

Termos para indexação: Vitis labrusca, área de superfície foliar, fenologia, índice de área foliar, trocas gasosas.

\section{Physiology and production of 'Niagara Rosada' grapevine in vertical shoot positioning and in Y-shaped training systems}

\begin{abstract}
The objective of this work was to characterize the physiological and productive variables of 'Niagara Rosada' vine (Vitis labrusca) trained in vertical shoot positioning (VSP) and in Y-shaped systems, in the first two years of production. In the 2014 and 2015 growing seasons, the following parameters were evaluated: leaf area index, photosynthesis, transpiration, stomatal conductance, leaf surface area, production variables, and fruit quality. In the first year of production, there were differences between the training systems for the ecophysiological variables affected by the leaf surface area of the canopies. In the second year of production, there were no differences between the ecophysiological variables. The number of clusters per leaf surface area, cluster mass, number of berries per cluster, and production per plant showed no differences between the training systems. Vines in the first and second years of production showed no differences between the two training systems for the relationships between leaf surface area and production; however, yield was higher in the VSP system because of the greater number of plants per hectare. Fruit produced in the Y-shaped system showed a greater amount of pigments, such as anthocyanins and flavonols, than those in the VSP system, with the same amount of total soluble solids.
\end{abstract}

Index terms: Vitis labrusca, leaf surface area, phenology, leaf area index, gas exchange.

\section{Introdução}

O Estado de São Paulo é o terceiro maior produtor de uvas do Brasil, com 154 mil toneladas produzidas em uma área de 8 mil hectares (IBGE, 2016). A produção paulista de uvas é voltada ao mercado de frutas frescas, em que a Niágara Rosada (Vitis labrusca L.) se destaca como a mais importante com $91,5 \%$ das plantas cultivadas, o que representa $33 \%$ de toda a produção nacional de uvas de mesa (IBGE, 2016; Instituto de Economia Agrícola, 2016).

O sistema de condução modifica a estrutura da videira no campo e interfere no espaçamento das plantas, na arquitetura da copa e na área foliar do dossel. Essas modificações relacionadas ao sistema adotado condicionam a eficiência da planta quanto à interceptação da radiação e, portanto, quanto à capacidade de conversão dessa energia e à partição 
da matéria seca produzida entre as partes da planta, o que define a sua produtividade (Reynolds \& Vanden Heuvel, 2009). O microclima no dossel também é modificado, com mudanças de intensidade de luz e de temperatura que atuam nos processos metabólicos dos frutos, o que interfere em sua qualidade, avaliada pelo teor de sólidos solúveis totais (Brix), flavonóis e antocianinas (Favero et al., 2010; Kyraleou et al., 2015).

No Brasil, o sistema de condução mais utilizado para 'Niágara Rosada' é o de espaldeira, em que as plantas são conduzidas em um único plano vertical. No entanto, com a utilização de porta-enxertos mais vigorosos, outros sistemas de condução vêm sendo adotados, como o de formato em Y, no intuito de alcançar o equilíbrio entre o vigor da planta e a produção. $\mathrm{O}$ sistema em Y é caracterizado por ter duas cortinas de ramos produtivos inclinados em $120^{\circ}$. Estudos com sistemas de condução em videiras têm mostrado que o Y proporciona um espaço maior para a planta vegetar (Pedro Júnior et al., 2007), o que melhora a qualidade dos cachos e favorece a produtividade (Palliotti, 2012; Hernandes et al., 2013), além de requerer menor uso de mão de obra em comparação à espaldeira (Hernandes $\&$ Pedro Junior, 2011). No entanto, faltam informações sobre a fisiologia e a produção das videiras nesses sistemas de condução.

O objetivo deste trabalho foi caracterizar as variáveis fisiológicas e produtivas da videira 'Niágara Rosada' (Vitis labrusca), nos sistemas de condução em espaldeira e em $\mathrm{Y}$, nos dois primeiros anos de produção.

\section{Material e Métodos}

O experimento foi desenvolvido na Escola Superior de Agricultura Luiz de Queiroz, Universidade de São

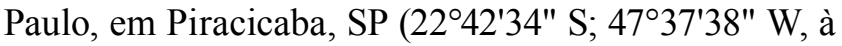
altitude de $546 \mathrm{~m}$ ), nos ciclos produtivos de 2014 e 2015. O clima, de acordo com a classificação de KöppenGeiger, é do tipo Cwa - tropical de altitude, com chuvas no verão e seca no inverno -, e a temperatura média do mês mais quente é superior a $22^{\circ} \mathrm{C}$ (Cepagri, 2016). A cultivar-copa utilizada foi a 'Niágara Rosada' (Vitis labrusca L.), enxertada sobre 'IAC 766 Campinas' [( . riparia $\mathrm{x}$ (V. rupestris $\mathrm{x}$ V. cordifolia) $-106-8 \mathrm{Mgt}]$ $\mathrm{x}$ ( . caribaea). A área experimental foi implantada em 2013, com mudas enxertadas e conduzidas em espaldeira e em Y. O sistema em espaldeira foi formado por mourões de eucalipto, a cada $5 \mathrm{~m}$ na linha, e por três fios de arame. Nesse sistema, as plantas foram conduzidas em cordão unilateral, no primeiro arame, a $1 \mathrm{~m}$ do solo, no espaçamento de $1 \mathrm{~m}$ entre plantas e $2 \mathrm{~m}$ entre linhas. $\mathrm{O}$ sistema em $\mathrm{Y}$ foi formado por estruturas de aço galvanizado, a cada $5 \mathrm{~m}$ na linha, com um fio de arame central e três fios em cada haste do Y. No sistema em Y, as plantas foram conduzidas em cordão unilateral no fio central, a 1,5 m do solo, no espaçamento de 1,2 m entre plantas e 3,2 $\mathrm{m}$ entre linhas. A área experimental foi composta por cinco parcelas, com três plantas por parcela, no total de 15 plantas por sistema de condução. As plantas foram submetidas às podas de produção curta (uma ou duas gemas por ramo produtivo) realizadas nos dias 13 de agosto de 2014 e 12 de agosto de 2015. Logo após as podas, aplicou-se cianamida hidrogenada a $5 \%$ de concentração sobre as gemas, para estimular a quebra de dormência e uniformizar a brotação. Para a padronização da produção das videiras, nos dois sistemas de condução adotados, deixaram-se, em média, oito ramos produtivos por metro linear de cordão. As adubações foram realizadas de acordo com a análise de solo e parceladas em três vezes, para a meta de produtividade entre 13 e $22 \mathrm{Mg} \mathrm{ha}^{-1}$. Aplicações regulares de fungicidas foram realizadas de acordo com a frequência de chuvas e a ocorrência de sintomas iniciais de doenças.

$O$ índice de área foliar (IAF) foi estimado com o uso do analisador de copa LAI-2000 (LI-COR, Lincoln, NE, EUA), nos estádios fenológicos de pleno florescimento, com bagas do tamanho de "grão de ervilha", no início da maturação, e frutos maduros, segundo a escala BBCH adaptada por Lorenz et al. (1995). A medição do IAF foi realizada nas três plantas de cada parcela, tendo-se utilizado o valor médio por parcela. A área de superfície foliar (AS) foi calculada a partir das dimensões da superfície foliar externa. Todas as secções do dossel foram aproximadas para retângulos, tendo-se calculado a área de cada um pela fórmula altura x comprimento, em metros quadrados (Smart, 1985). No sistema em espaldeira, utilizou-se a somatória das áreas do topo e das laterais, já que são os planos que interceptam a radiação solar. $\mathrm{O}$ cálculo da superfície foliar no sistema em Y baseouse unicamente na superfície foliar externa, posto que a luz incide sobre as duas cortinas inclinadas, e a parte inferior da vegetação se torna ineficaz na interceptação da radiação, capturando somente a 
radiação difusa (Smart, 1985). Realizou-se o cálculo da AS, para a área da parcela toda, ou seja, a área que continha três plantas, tendo-se utilizado o valor médio por planta. A taxa fotossintética $\left(\mathrm{A}, \mu \mathrm{mol} \mathrm{CO}_{2} \mathrm{~m}^{-2} \mathrm{~s}^{-1}\right)$, a transpiração $\left(\mathrm{E}, \mathrm{mmol} \mathrm{H}_{2} \mathrm{O} \mathrm{m}^{-2} \mathrm{~s}^{-1}\right)$ e a condutância estomática ( $\mathrm{gs}, \mathrm{mol} \mathrm{H}_{2} \mathrm{O} \mathrm{m}^{-2} \mathrm{~s}^{-1}$ ) foram avaliadas com o analisador portátil de gases por infravermelho (IRGA - infrared gas analyzer) Li-6400xt (LI-COR, Lincoln, NE, EUA), em duas folhas maduras, sadias e expostas à radiação solar máxima, no terço mediano do dossel vegetativo, em todas as plantas de cada parcela. As leituras foram realizadas entre 9:00 e 12:00 h, com o fluxo de fótons fotossintéticos ajustado para $1.000 \mu \mathrm{mol} \mathrm{m}{ }^{-2} \mathrm{~s}^{-1}$, a concentração de $\mathrm{CO}_{2}$ na câmara em torno de $400 \mu \mathrm{mol} \mathrm{mol}{ }^{-1}$, com a temperatura do ar externo, e com o uso de câmara com $6 \mathrm{~cm}^{2}$. Os estádios fenológicos avaliados foram floração total, bagas do tamanho de "grão de ervilha", início da maturação e frutos maduros para a colheita.

A colheita foi realizada quando os frutos apresentavam teor de sólidos solúveis mínimo de $14{ }^{\circ}$ Brix. Para a análise da produtividade, avaliaram-se: a produção por planta, o número de cachos por planta, a massa média dos cachos, o número de bagas por cacho, além da produtividade por hectare. Para a análise química dos frutos, colheram-se 10 bagas por parcela, no total de 50 bagas por sistema de condução. Avaliou-se o teor de sólidos solúveis totais ( ${ }^{\circ}$ Brix) em refratômetro portátil, e a acidez total titulável (percentagem de ácido tartárico) por titulação com $\mathrm{NaOH} 0,1 \mathrm{~N}$. As cascas foram utilizadas para determinar o conteúdo de antocianinas (mg $100 \mathrm{~g}^{-1}$ ) e flavonóis totais (mg $100 \mathrm{~g}^{-1}$ ) pelo método de Francis (1982). Avaliou-se a cor das bagas em um cacho marcado por parcela, e em cada cacho foram realizadas três leituras (acima, médio e abaixo), por meio do colorímetro Konica Minolta Chromameter CR-400. Com base nesses dados, calculou-se o índice específico para bagas de cor vermelha - CIRG (color index for red grapes) -, pela equação: $\mathrm{CIRG}=180$-hue*/(L*+C). Valores do índice CIRG próximos de zero correspondem a bagas de coloração verde, enquanto valores próximos de cinco, a bagas de coloração vermelha (Carreño et al., 1995).

Para as leituras das variáveis índice de área foliar, fotossíntese, transpiração e condutância estomática, realizadas ao longo do tempo, calculou-se os valores da área abaixo da curva, que foram comparadas por meio da análise de variância e teste de Tukey, a 5\% de probabilidade. As variáveis de área de superfície foliar, produção e qualidade de frutos foram avaliadas no dia da colheita, tendo-se apresentado as médias dos dois anos de avaliação, quando não houve interação entre ano e sistema de condução. As médias foram comparadas pela análise da variância multivariada com teste de Tukey, a 5\% de probabilidade. Utilizou-se o pacote estatístico SAS 9.0 (SAS Institute Inc., Cary, NC, EUA).

\section{Resultados e Discussão}

As videiras conduzidas nos dois sistemas de condução, no primeiro ano de produção (2014), tiveram o mesmo índice de área foliar (IAF). Entretanto, no segundo ano de produção (2015), os valores observados no sistema em $\mathrm{Y}$ foram superiores aos observados no sistema em espaldeira (Figura 1 e Tabela 1). Os resultados do primeiro ano podem ser explicados pelo estádio inicial de desenvolvimento das plantas, que estavam ainda em fase de formação de suas estruturas permanentes. No segundo ano de produção, as plantas com três anos de idade, já formadas, apresentaram diferentes IAF entre os sistemas. Em experimento com a uva 'Niágara Rosada', enxertada sobre 'IAC 766 Campinas', com oito anos de idade, no Município de Jundiaí, SP, observou-se que o maior número de ramos por planta, no sistema em Y, induziu o aumento de $46 \%$ do índice de área foliar em relação ao sistema em espaldeira (Pedro Júnior et al., 2007). Portanto, espera-se que plantas com maior idade apresentem comportamento similar ao reportado anteriormente.

Embora o IAF seja útil para comparar as características do dossel de videiras cultivadas em sistemas de condução semelhantes, uma grande desvantagem de seu uso é o fato de ele não levar em consideração o volume de copa ou a quantidade de espaço alocado para a distribuição do dossel (Schultz et al., 2009). Uma avaliação com precisão da quantidade de superfície de folhas é crítica, especialmente quando se comparam sistemas de condução de várias configurações e tamanhos de copa (Gladstone \& Dokoozlian, 2003). A área de superfície foliar (AS), expressa em metros quadrados por planta, é um critério utilizado para estimar a quantidade de folhas expostas que são úteis na captura da luminosidade, sem importar a forma da cobertura, o que permite avaliar o potencial qualitativo do sistema de condução 
(Smart \& Robinson, 1991). No presente experimento, para os dois anos de avaliação, o valor de AS foi $27 \%$ maior no sistema em Y, com média de $3,4 \mathrm{~m}^{2}$ por
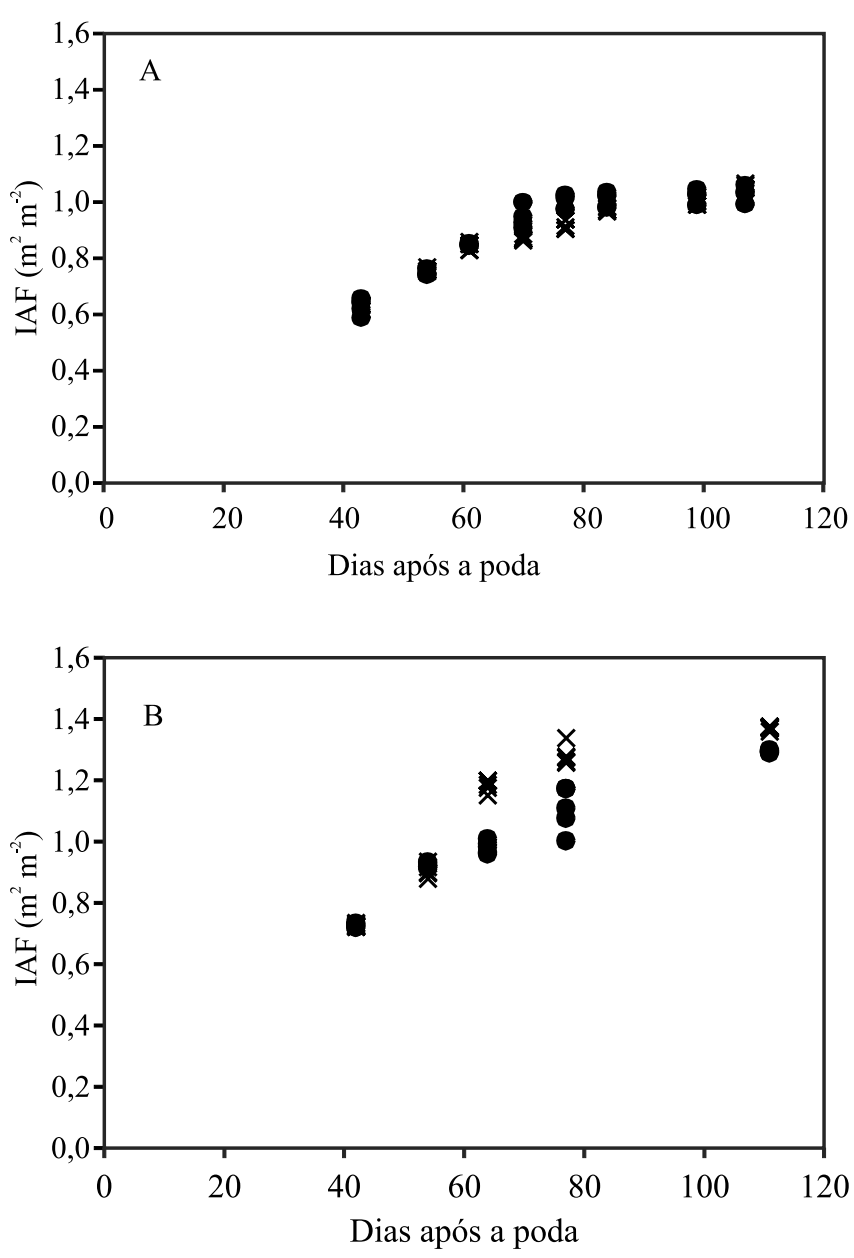

$\mathrm{X}^{\prime} \mathrm{Y}^{\prime}$ OEspaldeira

Figura 1. Índice de área foliar (IAF) da videira 'Niágara Rosada' conduzida em espaldeira e em Y, em dois anos de avaliação - 2014 (A) e 2015 (B) -, em Piracicaba, SP. planta, do que o obtido pelo sistema em espaldeira, que apresentou valor médio de $2,5 \mathrm{~m}^{2}$ por planta. Valores similares foram encontrados em videiras 'Sangiovese' cultivadas na Itália, com AS de $4,2 \mathrm{~m}^{2}$ por planta, na condução em Y, e $2,8 \mathrm{~m}^{2}$ por planta em sistema em espaldeira, o que representa o incremento de $52 \%$ na área de superfície do dossel (Palliotti, 2012). Na França, videiras da uva 'Semillon', conduzidas no sistema em lira aberta, que tem uma arquitetura similar ao Y, a AS foi em média $45 \%$ superior à de videiras conduzidas no sistema em espaldeira (Rosier \& Carbonneau, 1995). Os autores atribuem o resultado à menor aglomeração da vegetação no sistema em lira e, portanto, melhor exposição das folhas à luz solar. Em sistemas de dossel dividido, há incremento do volume ou da quantidade de espaço disponível para a distribuição das folhas, graças aos dois planos oblíquos de vegetação, que reduzem a densidade da copa e melhoram a exposição à luz solar e o microclima interno. Em sistemas verticais, ocorre adensamento dos ramos entre os arames que suportam a folhagem, o que restringe o volume do dossel e limita a área disponível para sua distribuição (Gladstone \& Dokoozlian, 2003).

Quanto às trocas gasosas, avaliadas pela fotossíntese (A) e a transpiração (E), as videiras conduzidas em espaldeira, no primeiro ciclo de produção (2014), apresentaram médias superiores às obtidas em videiras conduzidas em Y (Tabela 1 e Figura 2). $\mathrm{O}$ ano de 2014 apresentou um volume de chuvas menor, o que pode ter interferido nesses resultados. O sistema em Y, por apresentar maior AS em relação ao sistema em espaldeira, no primeiro ano de produção, pode ter causado maior sensibilidade à falta de água pelas plantas. Essa sensibilidade pode ser observada pela menor condutância estomática (gs) e menor taxa de transpiração (E), a fim de evitar perda de água. Valores superiores de transpiração em sistemas de condução com menor área de superfície foliar, como é o caso

Tabela 1. Área abaixo da curva das variáveis de índice de área foliar, fotossíntese, transpiração e condutância estomática da videira 'Niágara Rosada' conduzida em espaldeira e em Y, em dois anos de avaliação, em Piracicaba, SP.

\begin{tabular}{|c|c|c|c|c|c|c|c|c|}
\hline \multirow[t]{2}{*}{ Sistema de condução } & \multicolumn{2}{|c|}{ Índice de área foliar } & \multicolumn{2}{|c|}{ Fotossíntese (A) } & \multicolumn{2}{|c|}{ Transpiração (E) } & \multicolumn{2}{|c|}{ Condutância estomática (gs) } \\
\hline & 2014 & 2015 & 2014 & 2015 & 2014 & 2015 & 2014 & 2015 \\
\hline Espaldeira & 56,2 & 73,6 & 795,4 & 1047,5 & 163,1 & 485,4 & 12,4 & 485,4 \\
\hline $\mathrm{Y}$ & 55,3 & 81,2 & 695,9 & 1005,7 & 141,5 & 469,4 & 9,4 & 469,4 \\
\hline Sistema & ns & $*$ & $*$ & $\mathrm{~ns}$ & $*$ & $\mathrm{~ns}$ & $*$ & $\mathrm{~ns}$ \\
\hline
\end{tabular}

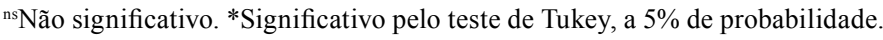



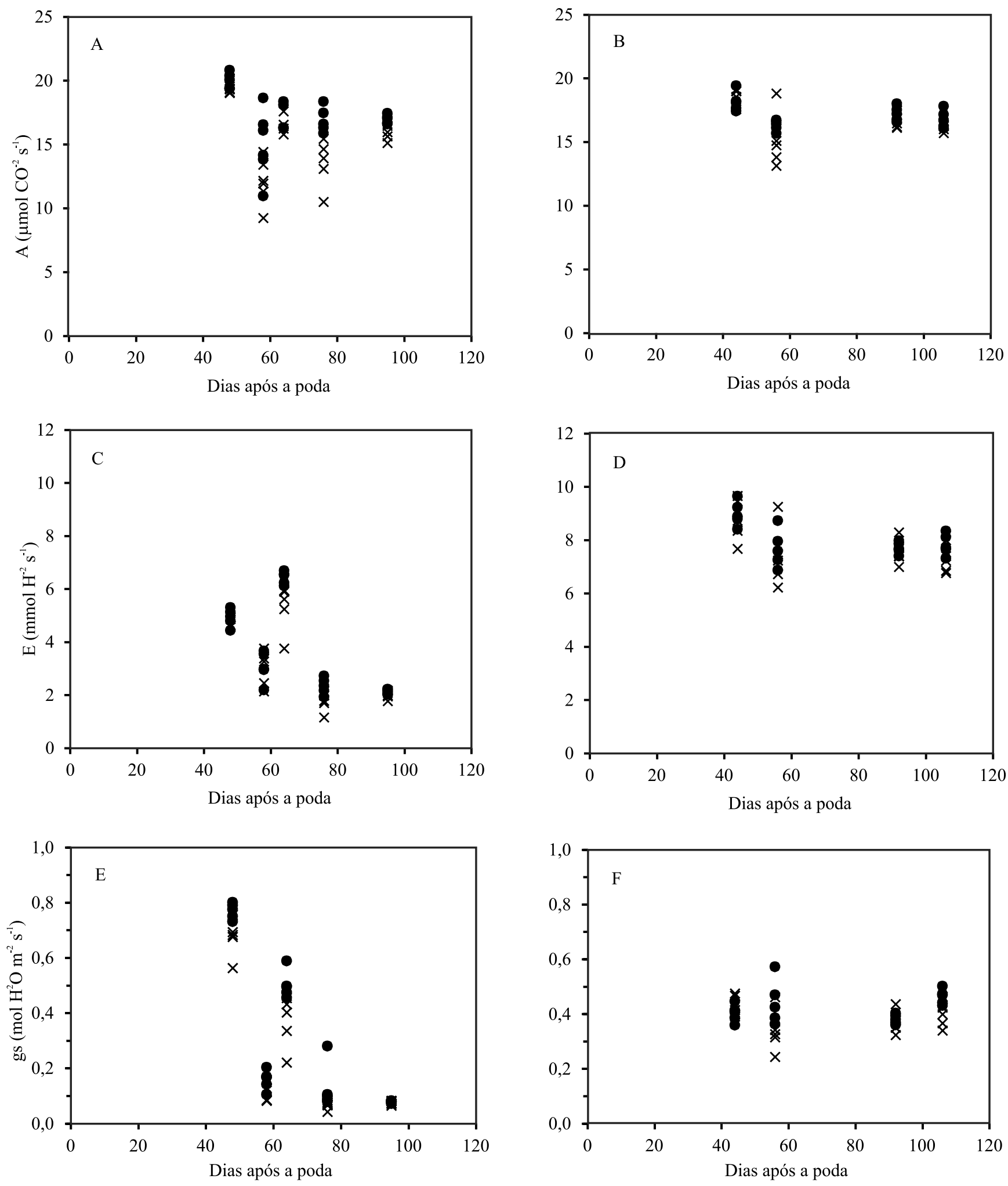

$\mathbf{x}^{\prime} \mathrm{Y}^{\prime} \bullet$ Espaldeira

$\mathbf{x}^{\prime} \mathrm{Y}^{\prime} \bullet$ Espaldeira

Figura 2. Videiras 'Niágara Rosada' conduzidas em espaldeira e em Y, em dois anos de avaliação, 2014 (A, C e E) e 2015 (B, D e F), em Piracicaba, SP. “A”, fotossíntese (A e B); “E”, transpiração (C e D); e "gs”, condutância estomática (E e F). 
de videiras em espaldeira, foram observados por Baeza et al. (2005). Os autores concluíram que uma área menor de superfície do dossel permite maior disponibilidade de água à planta, o que possibilita maior taxa de transpiração. Esta resposta da transpiração foi explicada pela maior temperatura do ambiente, maior exposição ao vento e menor sombreamento do solo. No segundo ano de produção (2015), os valores de trocas gasosas e condutância estomática não foram afetados pelo sistema de condução, provavelmente em virtude da disponibilidade hídrica pelo aumento da quantidade de chuva.

Os dois sistemas de condução avaliados não limitaram as trocas gasosas nem a condutância estomática, realizadas pelas videiras para essa cultivar, em condições agronômicas e hídricas ótimas para a cultura, o que corrobora os resultados obtidos por Norberto et al. (2009). Esses autores observaram valores similares de fotossíntese, em videiras de 'Niágara Rosada' conduzidas em pérgula, espaldeira e em lira, que variaram entre 7 e $10 \mu \mathrm{mol} \mathrm{CO}_{2} \mathrm{~m}^{-2} \mathrm{~s}^{-1}$, e de condutância estomática, entre 0,5 e $1 \mathrm{~mol} \mathrm{H}_{2} \mathrm{O} \mathrm{m}^{-2} \mathrm{~s}^{-1}$. Deus (2014) observou em plantas de 'Niágara Rosada', conduzidas em pérgula com ou sem cobertura plástica, valores de fotossíntese entre 8 e $16 \mu \mathrm{mol} \mathrm{CO} \mathrm{Cm}^{-2} \mathrm{~s}^{-1}$.

Em ambos os sistemas de condução, a colheita da uva 'Niágara Rosada' ocorreu no primeiro ciclo de produção, em 15 de dezembro de 2014 e, no segundo ciclo de produção, em 14 de dezembro de 2015. O número de cachos por planta foi maior no sistema em Y, em consequência do maior comprimento do cordão, que foi de $1,2 \mathrm{~m}$, enquanto o da espaldeira foi de $1,0 \mathrm{~m}$; entretanto, os dois sistemas produziram a mesma quantidade de cachos por metro quadrado de área de superfície foliar (Tabela 2). A massa de cachos, o número de bagas por cacho e a produção por planta não apresentaram diferenças entre videiras, nos dois sistemas de condução. Em videiras 'Niágara
Rosada' com onze anos de idade, conduzidas no sistema em $\mathrm{Y}$, a produção por planta e a produtividade por hectare foram maiores do que as de videiras conduzidas no sistema em espaldeira (Hernandes et al., 2013). Em videiras com oito anos de idade, o sistema de dossel dividido em lira também resultou em maior produtividade do que pelo sistema em espaldeira, em decorrência do maior número e massa de cachos por planta (Mota et al., 2010). Em estudos realizados na Itália, plantas da uva 'Sangiovese', com cinco anos de idade e conduzidas em Y apresentaram produção de frutos por planta $13 \%$ maior, graças à maior massa de cachos e de bagas, em comparação ao sistema vertical, porém, a produtividade não diferiu, em razão do menor número de plantas por hectare (Palliotti, 2012). A diferença observada nos resultados do presente trabalho, em relação aos demais reportados, provavelmente está relacionada à idade das plantas. Neste trabalho, foram avaliadas videiras no primeiro e segundo anos de produção em que, provavelmente, ocorreu maior gasto de energia em plantas conduzidas no sistema em Y, cuja área é maior para a formação de sua estrutura vegetativa, em relação ao sistema em espaldeira. Esse gasto de energia é suprido pelas reservas de carboidratos da planta para o crescimento e desenvolvimento dos órgãos vegetativos, como tronco, raízes, cordão, ramos e folhas (Keller, 2015). Nos primeiros anos, a planta ainda está em formação de suas estruturas, com poucas reservas e poucos órgãos produtivos, o que pode ter acarretado as baixas produções. Em plantas já formadas, a produção tende a crescer e a apresentar maiores diferenças de desenvolvimento e de produção das videiras entre os sistemas de condução (Keller, 2015).

Podem-se avaliar as diferenças de produção relacionadas ao sistema de condução pela relação entre a superfície foliar (AS) e a produção. Esse índice

Tabela 2. Variáveis de produção da videira 'Niágara Rosada' conduzida em espaldeira e em Y, em Piracicaba, SP.

\begin{tabular}{|c|c|c|c|c|c|c|}
\hline $\begin{array}{l}\text { Sistema } \\
\text { de condução }\end{array}$ & $\begin{array}{c}\text { Número de cachos } \\
\text { por planta }\end{array}$ & $\begin{array}{l}\text { Número de cachos } \\
\left(\mathrm{m}^{-2} \text { de folha }\right)\end{array}$ & $\begin{array}{l}\text { Massa de cacho } \\
(\mathrm{g})\end{array}$ & $\begin{array}{c}\text { Numero de bagas } \\
\text { (cacho) }\end{array}$ & $\begin{array}{c}\text { Produção } \\
\text { (kg por planta) }\end{array}$ & $\begin{array}{l}\text { Produtividade } \\
\left(\mathrm{Mg} \mathrm{ha}^{-1}\right)\end{array}$ \\
\hline Espaldeira & $12,5^{(1)}$ & 5,0 & 212,6 & 51,4 & 2,3 & 11,2 \\
\hline $\mathrm{Y}$ & 16,8 & 5,1 & 196,1 & 47,4 & 2,6 & 6,8 \\
\hline Sistema & $*$ & ns & ns & $\mathrm{ns}$ & ns & $*$ \\
\hline Sistema $\mathrm{x}$ ano & $\mathrm{ns}$ & ns & $\mathrm{ns}$ & ns & $\mathrm{ns}$ & $\mathrm{ns}$ \\
\hline
\end{tabular}

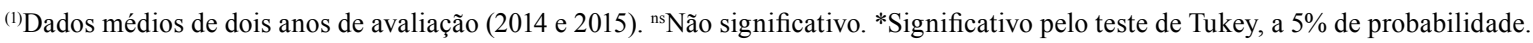


é útil para quantificar ou explicar as diferenças de comportamento da videira avaliada em diferentes arquiteturas do dossel (Smart \& Robinson, 1991; Palliotti, 2012). Na relação entre AS e a produção, não houve diferença nos dois anos de avaliação entre os sistemas de condução em Y e em espaldeira (Tabela 3). Sistemas de formação com dossel dividido, como o $\mathrm{Y}$, apresentam maior percentagem de área foliar em saturação de luz do que sistemas de dossel individual e, teoricamente, espera-se menor relação da superfície de área foliar por quilo de fruto produzido (Kliewer \& Dokoozlian, 2005). Esse resultado foi observado por Favero et al. (2010), que encontraram, para videiras conduzidas em sistema de dupla cortina (GDC), o valor de $1,0 \mathrm{~m}^{2}$ de área foliar por quilograma de fruto, enquanto, para o sistema em espaldeira, essa proporção aumentou para $1,4 \mathrm{~m}^{2}$ de área foliar por quilograma de fruto. Kliewer \& Dokoozlian (2005) relataram que a área foliar necessária para atingir o nível máximo de açúcares solúveis, massa de baga e coloração à colheita deve estar entre 0,5 a $0,8 \mathrm{~m}^{2} \mathrm{~kg}^{-1}$, para GDC, e 0,8 a $1,2 \mathrm{~m}^{2} \mathrm{~kg}^{-1}$ para espaldeira. Nos dois anos de avaliação, as plantas apresentaram valores superiores aos mencionados nos demais estudos, porém compatíveis

Tabela 3. Relações entre a produção de fruto e a área de superfície foliar da videira 'Niágara Rosada' conduzida em espaldeira e em Y, em dois anos de avaliação, em Piracicaba, SP.

\begin{tabular}{|c|c|c|c|}
\hline Sistema de condução & 2014 & 2015 & Ano \\
\hline \multicolumn{4}{|c|}{ ( $\mathrm{m}^{2}$ folha $\mathrm{kg}^{-1}$ fruto) } \\
\hline Espaldeira & 0,9 & 1,7 & $*$ \\
\hline $\mathrm{Y}$ & 1,5 & 1,5 & $\mathrm{~ns}$ \\
\hline Sistema & $\mathrm{ns}$ & ns & \\
\hline
\end{tabular}

com a idade das plantas. A tendência é que a relação entre área foliar e produção caia, em ambos os sistemas de condução, e que haja diferenciação entre eles com as plantas mais velhas.

Quanto à qualidade dos frutos, o teor de sólidos solúveis e a acidez titulável não apresentaram diferenças entre os sistemas de condução. As quantidades de flavonóis e antocianinas, em frutos de videiras conduzidas no sistema em Y, foram 7 e $18 \%$ superiores às dos frutos em espaldeira, respectivamente (Tabela 4). Esses resultados corroboram os de Kyraleou et al. (2015), que reportam melhoria da quantidade de antocianinas na uva 'Xinomavro', conduzida no sistema em lira, em comparação ao sistema em espaldeira. $\mathrm{O}$ incremento de antocianinas pode estar relacionado às baixas temperaturas das bagas durante o estádio de amadurecimento, especialmente durante as horas mais quentes do dia, pois a inclinação das cortinas vegetais do sistema em Y cria um ambiente sombreado na zona dos cachos (Palliotti, 2012). Outro fator importante para o desenvolvimento dos pigmentos da cor das bagas de videiras tintas é o equilíbrio entre a superfície foliar e o volume do dossel, o que aumenta a proporção de folhas externas e melhora o balanço de carbono da planta. (Gladstone \& Dokoozlian, 2003; Reynolds \& Vanden Heuvel, 2009). De acordo com os resultados da quantidade de pigmentos de cor nos frutos, o sistema em Y, provavelmente, atinge melhor este equilíbrio do que o sistema em espaldeira. Porém, os resultados do índice de cor (CIRG) não refletiram as diferenças de pigmentação, pois não houve diferenças entre os sistemas de condução (Tabela 4). É importante levar em consideração que foram avaliados o primeiro e o segundo ciclos produtivos das videiras 'Niágara Rosada'. Esses resultados têm como importância a comparação de sistemas de condução no início da produção.

Tabela 4. Variáveis de qualidade do fruto da videira 'Niágara Rosada' conduzida em espaldeira e em Y, em Piracicaba, SP.

\begin{tabular}{lccccc}
\hline Sistema de condução & $\begin{array}{c}\text { Sólidos solúveis } \\
\left({ }^{\circ} \text { Brix }\right)\end{array}$ & $\begin{array}{c}\text { Acidez titulável } \\
(\%)\end{array}$ & $\begin{array}{c}\text { Antocianinas totais } \\
\left(\mathrm{mg} \mathrm{100} \mathrm{g}^{-1}\right)\end{array}$ & $\begin{array}{c}\text { Flavonóis } \\
\left(\mathrm{mg} \mathrm{100} \mathrm{g}^{-1}\right)\end{array}$ \\
\hline Espaldeira & $16,4^{(1)}$ & 0,5 & 30,9 & 55,9 & CIRG \\
Y & 16,9 & 0,5 & 37,8 & 60,1 & 4,2 \\
\hline Sistema & $\mathrm{ns}$ & $\mathrm{ns}$ & $*$ & $*$ & $\mathrm{~ns}$ \\
Sistema x ano & $\mathrm{ns}$ & $\mathrm{ns}$ & $\mathrm{ns}$ & $\mathrm{ns}$ & $\mathrm{ns}$ \\
\hline
\end{tabular}

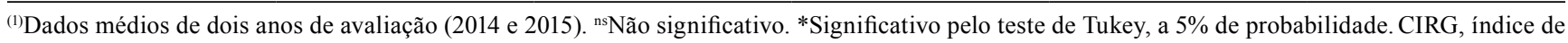
cor. 


\section{Conclusões}

1. No primeiro e segundo ciclos produtivos, os sistemas de condução em espaldeira e em Y apresentam relações iguais entre a área de superfície foliar e a produção, em videiras de 'Niágara Rosada'; a eficiência de produção por área de superfície foliar é a mesma entre os dois sistemas de condução; e a produtividade é superior no sistema em espaldeira, em função da maior quantidade de videiras por hectare.

2. Frutos produzidos no sistema em Y apresentam maior quantidade de pigmentos, como antocianinas e flavonóis, do que no sistema em espaldeira, com a mesma a quantidade de sólidos solúveis totais na colheita.

\section{Agradecimentos}

À Fundação de Amparo à Pesquisa do Estado de São Paulo (Fapesp, processo $n^{\circ}$ 2014/08190-6; 2013/24003-9), pelo apoio financeiro.

\section{Referências}

BAEZA, P.; RUIZ, C.; CUEVAS, E.; SOTÉS, V.; LISSARRAGUE, J.-R. Ecophysiological and agronomic response of Tempranillo grapevines to four training systems. American Journal of Enology and Viticulture, v.56, p.129-138, 2005.

CARREÑO, J.; MARTÍNEZ, A.; ALMELA, L.; FERNÁNDEZLÓPEZ, J.A. Proposal of an index for the objective evaluation of the colour of red table grapes. Food Research International, v.28, p.373-377, 1995. DOI: 10.1016/0963-9969(95)00008-A.

CEPAGRI. Centro de Pesquisas Meteorológicas e Climáticas Aplicadas à Agricultura. Clima dos municípios paulistas. Disponível em: <http://www.cpa.unicamp.br/outras-informacoes/ clima_muni_436.html>. Acesso em: 28 mar. 2016.

DEUS, B.C. da S. de. Capacidade fotossintética e ontogenia foliar da videira 'Niágara Rosada' cultivada sob cobertura plástica no Norte Fluminense. 2014. 54p. Dissertação (Mestrado) - Universidade Estadual do Norte Fluminense Darcy Ribeiro, Campos dos Goytacazes.

FAVERO, A.C.; AMORIM, D.A. de; MOTA, R.V. da; SOUZA, C.R. de; REGINA, M. de A. Physiological responses and production of 'Syrah' vines as a function of training systems. Scientia Agricola, v.67, p.267-273, 2010. DOI: 10.1590/s010390162010000300003.

FRANCIS, F.J. Analysis of anthocyanins. In: MARKAKIS, P. (Ed.). Anthocyanins as food colors. New York: Academic Press, 1982. p.181-207. DOI: 10.1016/B978-0-12-472550-8.50011-1.

GLADSTONE, E.A.; DOKOOZLIAN, N.K. Influence of leaf area density and trellis/training system on the light microclimate within grapevine canopies. Vitis - Journal of Grapevine Research, v.42, p.123-131, 2003.

HERNANDES, J.L.; PEDRO JÚNIOR, M.J. Sistema de condução em manjedoura na forma de "Y" e cultivo protegido para a videira. Campinas: Instituto Agronômico, 2011. 42 p. (Série Tecnologia APTA. Boletim Técnico IAC, 211).

HERNANDES, J.L.; PEDRO JÚNIOR, M.J.; BLAIN, G.C.; ROLIM, G. de S. Comportamento produtivo da videira 'Niágara Rosada' em diferentes sistemas de condução, com e sem cobertura plástica, durante as safras de inverno e de verão. Revista Brasileira de Fruticultura, v.35, p.123-130, 2013. DOI: 10.1590/ s0100-29452013000100015.

IBGE. Instituto Brasileiro de Geografia e Estatística. Banco de Dados Agregados. Sistema IBGE de Recuperação Automática - SIDRA. Disponível em: <http://www.sidra.ibge.gov.br/bda/ tabela/protabl.asp? $=1613 \& \mathrm{z}=\mathrm{t} \& \mathrm{o}=11 \& \mathrm{i}=\mathrm{P}>$. Acesso em: $24 \mathrm{mar}$. 2016.

IEA. Instituto de Economia Agrícola. Estatísticas da produção paulista. Disponível em: <http://ciagri.iea.sp.gov.br/nial/ subjetiva.aspx?cod_sis=1\&idioma=1>. Acesso em: 24 mar. 2016.

KELLER, $M$. The science of grapevines: anatomy and physiology. 2.ed. Amsterdam: Academic Press, 2015. 509p.

KLIEWER, W.M.; DOKOOZLIAN, N.K. Leaf area/crop weight ratios of grapevines: Influence on fruit composition and wine quality. American Journal of Enology and Viticulture, v.56, p.170-181, 2005.

KYRALEOU, M.; KALLITHRAKA, S.; KOUNDOURAS, S.; CHIRA, K.; HAROUTOUNIAN, S.; SPINTHIROPOULOU, H.; KOTSERIDIS, Y. Effect of vine training system on the phenolic composition of red grapes (Vitis vinifera L. cv. Xinomavro). Journal International des Sciences de la Vigne et du Vin, v.49, p.71-84, 2015. DOI: 10.20870/oeno-one.2015.49.2.92.

LORENZ, D.H.; EICHHORN, K.W.; BLEIHOLDER, H.; KLOSE, R.; MEIER, U.; WEBER, E.W. Phenological growth stages of the grapevine (Vitis vinifera L. ssp. vinifera)- Codes and descriptions according to the extended BBCH scale. Australian Journal of Grape and Wine Research, v.1, p.100-103, 1995. DOI: 10.1111/ j.1755-0238.1995.tb00085.x.

MOTA, R.V. da; SILVA, C.P.C.; CARMO, E.L. do; FONSECA, A.R.; FAVERO, A.C.; PURGATTO, E.; SHIGA, T.M.; REGINA, M. de A. Composição de bagas de 'Niágara Rosada' e 'Folha-deFigo' relacionadas ao sistema de condução. Revista Brasileira de Fruticultura, v.32, p.1116-1126, 2010. DOI: 10.1590/S010029452011005000010.

NORBERTO, P.M.; REGINA, M. de A.; CHALFUN, N.N.J.; SOARES, A.M. Efeito do sistema de condução em algumas características ecofisiológicas da videira (Vitis labrusca L.). Ciência e Agrotecnologia, v.33, p.721-726, 2009. DOI: 10.1590/ S1413-70542009000300009.

PALLIOTTI, A. A new closing Y-shaped training system for grapevines. Australian Journal of Grape and Wine Research, v.18, p.57-63, 2012. DOI: 10.1111/j.1755-0238.2011.00171.x.

PEDRO JÚNIOR, M.J.; HERNANDES, J.L.; TECCHIO, M.A.; PEZZOPANE, J.R.M. Influência do sistema de condução no 
microclima, na produtividade e na qualidade de cachos da videira 'Niágara Rosada', em Jundiaí-SP. Revista Brasileira de Fruticultura, v.29, p.313-317, 2007. DOI: 10.1590/S010029452007000200024.

REYNOLDS, A.G.; VANDEN HEUVEL, J.E. Influence of grapevine training systems on vine growth and fruit composition: a review. American Journal of Enology and Viticulture, v.60, p.251-268, 2009.

ROSIER, J.P.; CARBONNEAU, A. Medidas de superfície foliar na comparação de dois sistemas de condução da videira cultivada em solos argiloso e arenoso. Revista Ceres, v.42, p.253-262, 1995.
SCHULTZ, H.R.; PIERI, P.; PONI, S.; LEBON, E. The ecophysiology of grapevine canopy systems - learning from models -. In: RECENT ADVANCES IN GRAPEVINE CANOPY MANAGEMENT, 2009, Davis. [Anais]. Davis: University of California, 2009. p.7-12. Organizers N. Dokoozlian, J. Wolpert.

SMART, R.; ROBINSON, M. Sunlight into wine: a handbook for wine grape canopy arrangement. Adelaide: Winetitles, 1991. 88p.

SMART, R.E. Principles of grapevine canopy microclimate manipulation with implications for yield and quality: a review. American Journal of Enology and Viticulture, v.36, p.230-239, 1985.

Recebido em 27 de maio de 2016 e aprovado em 27 de julho de 2016 